\title{
Twin Paternity; Twin Study Summaries; Why Twins Fascinate
}

\author{
Nancy L. Segal \\ Department of Psychology, California State University, United States of America
}

\begin{abstract}
$\Lambda \mathrm{n}$ unusual case of uncertain twin paternity is presented. New research on inbred strains of mice may hold important clues Afor paternity testing of twins in the future. Next, four recent twin studies examining selected topics in autism, color perception, language development and high-order pregnancy risk are reviewed. Finally, several unusual twin-related situations are variously considered with respect to their research significance and practical applications.
\end{abstract}

\section{Twin Paternity: Who's the Father?}

A European journalist described an unusual case: A woman had had intercourse with monozygotic (MZ) twin brothers on the same day and became pregnant. She is now the mother of a young daughter. The court conducted DNA tests in order to assign paternity, but concluded (correctly) that either of the two twins could have fathered the child.

Comment: Did the Portuguese courts conclude correctly that identifying the child's father was an impossible task? Yes for now, but perhaps no for the future. Raykan et al. (2002) have shown that in inbred mice, some alleles vary in their expressivity, despite their lack of genetic heterogeneity. This variable expressivity results from epigenetic processes (turning on and turning off of genes due to changes in environments; see Gottesman, 1991). Raykan et al. suggest that such processes occur during embryogenesis and that such alleles should be called metastable epialleles _ epialleles are alleles that can exist in more than one state, while metastable epialleles are alleles whose epige- netic state can change and be passed on genetically. They point out that such effects are hard to detect unless genetic and environmental differences between organisms are small. At the human level, this would only be possible with $\mathrm{MZ}$ twins. If such effects were detectable with precision, then we might be able to answer the question: Who's the father? (Nick Martin brought this fascinating case to my attention and referred me to the research team investigating epialleles.)

In some ways, this family situation mimics that of the $\mathrm{MZ}$ twin-family design. When MZ male twins marry nontwin spouses their children become genetic halfsiblings and twins become genetic fathers to their nieces and nephews. By gathering many such families it becomes possible to conduct a variety of informative comparisons, such as the relative resemblance between children to the rearing father (with whom children share genes and environments) and the paternal uncle (with whom children share only genes). However, assembling large numbers of cases in which the father's identity is questionable (as in the case described above) is very unlikely. In the rare event that a sample of such families could be found, the best research situation for behavioralgenetic studies would involve children living with one alleged twin father, but not with the other. Of course, even in ordinary twinfamily studies it is impossible to know with scientific certainty who fathered which child.

An even more provocative case concerns a MZ male twin who received a testicle transplant from his brother, enabling him to become a father (Silber, 1978). The identity of the legal father could not be questioned, but the identity of the biological one could be an intriguing topic for discussion. 


\section{Twin Study Summaries}

\section{Autism}

A genetic component to autism has been well established by virtue of twin studies showing $36 \%$ to $91 \% \mathrm{MZ}$ twin concordance, and $0 \%$ to $24 \%$ dizygotic (DZ) twin concordance. However, neuroanatomical features associated with the narrow and broad forms of the disorder are less well known. A recent twin study by Kates et al. (2004) has helped to inform this question.

Participants included $16 \mathrm{MZ}$ twin pairs and 16 matched singletons. (Unfortunately, methods for diagnosing the zygosity of the twins were not described.) The individuals ranged in age from 5 to 14 years. Seven twin pairs were clinically concordant for the narrow form of autism, while the remaining nine pairs were discordant. All participants underwent magnetic resonance imaging (MRI). A major finding was that all twin pairs were concordant for cerebral gray and white matter volumes; however, only the clinically concordant twin pairs were also concordant for cerebellar gray and white matter volumes. (White brain matter carries information between the nerve cells of the brain; gray brain matter is part of the 'thinking brain' and looks gray because it is composed of nerve cells and blood vessels; OMD, 1997-2004.)

The reasons why clinically discordant MZ twins might show neuroanatomical differences are unknown. The investigators suggested that these effects might arise from within-pair differences in susceptibility genes affecting brain development, or from environmental trauma affecting one susceptible co-twin.

It was also of interest that both members of the discordant twin pairs showed white matter volumes that were below those of the control subjects. This finding was consistent with the cognitive deficits characteristic of autistic children. (A possible caveat was the marked IQ discrepancy between the autistic and control children.) However, it was also unclear why the group difference was limited to white brain matter. Additional studies using larger twin and nontwin samples would supplement this important work.

\section{Color Perception}

Twins help us understand the way we see the world around us. A recent twin study by Galina Paramei (2004) from Otto-von-Guericke University in Magdeburg, Germany and colleagues used twin and sibling pairs to understand individual differences in color perception. Participants included four $\mathrm{MZ}$ twin pairs, three $\mathrm{DZ}$ twin pairs, one ordinary sibling pair and three unrelated individuals. The twins, siblings and singletons were presented with pairs of lights, drawn from an array of 13, and asked to judge the similarity of these stimuli on a 1 to 9 scale $(1$ - minimal difference; 9 - maximal difference). Each pair of colored lights was presented eight times during the test session.

MZ twins showed higher similarity in their similarity judgments than DZ twins (.94 to .97 vs. .72 to .82 ). The pair of nontwin siblings (.75) did not differ from the DZ twins. Color spaces were also mapped for the 14 twin individuals, two siblings and one unrelated individual.

\section{Private Speech}

The study summarized here is a guest entry from J. Susan Griffith, M.D., from the National Organization of Mothers of Twins Clubs (NOMOTC). Its purpose was to investigate the nature of private language among multiples. A questionnaire directed to parents of multiples was printed in NOMOTC's bi-monthly publication and in a national mailing to all member clubs. A total of 445 surveys were received and included the following participant classifications: twins - 421, triplets - 21, quadruplets - 3; zygosity: identical - 133, fraternal - 294, unknown - 18; gender: male - 161, female - 133, boy/girl - 14; premature birth $55 \%$; developmental delays - 10\%; age range -3 months to 27 years.

Approximately half the multiple birth parents indicated that their chil- dren had shown a type of private language or 'twin talk'. A large percentage of mothers $(83 \%)$ did not seek help when the behavior developed. Only $4 \%$ of the multiples experienced negative effects on their relationships with family and/or friends because of their 'twin talk'. Slightly over half of the parents indicated that the private language between their multiples was ongoing, but one third said it had disappeared by the age of 36 months.

There is considerable debate over whether 'twin talk' or the private language really exists, or if it is part of the developmental delay in speech that occurs more often in multiples. Results from this survey and other research studies are divided on this issue. Multiples, particularly males, are more likely to have speech and language problems than singletons for many reasons, including prematurity, mimicking their twin (with whom they spend most of their time) and less oneon-one interaction with adults.

We suggest that multiples be screened for language delays, and speech therapy be initiated, if needed. Most multiples communicate well in their native language by the time they reach kindergarten. One mother said, 'It seems as though the twin talk decreased as their (use of the) English language increased'.

Comment by NLS: The language development of twins and other multiples is extremely complex behavior. Complete description of the behavior in question is required. Thorpe et al. (2001) distinguished between two types of 'secret language' utterances:

1. Private language: communication used exclusively within the child pair, but which is unintelligible to others.

2. Shared verbal understanding: communication used within the pair and with others, but which is unintelligible to others. The investigators concluded that shared verbal understanding is a normal developmental feature in twins and near-in-age siblings. In contrast, private language is less frequent (although assessment 
may be problematic at 20 months of age when children are learning to talk).

Individuals interested in learning additional details about the NOMOTC study should contact J. Susan Griffith, M.D.: s.griffin3@insightbb.com

\section{Higher-Order Multiple Pregnancies}

Multiple birth pregnancies pose risks to mothers and babies. Wen et al. (2004) from the University of Ottawa, in Canada, and colleagues compared maternal morbidity and risk complications in mothers deliver- ing twins, quadruplets and more. Their data were drawn from United States Multiple Birth File, established by the Center for Disease Control and Prevention, and spanned the years 1995 to 1997 . Multiple birth sets were matched across numerous characteristics, including plurality, place of birth, maternal age and maternal weight gain. The final sample included 158,152 multiple birth mothers.

The main findings were that women delivering triplets, quadruplets, and other higher-order sets showed an increase in birth complica- tions. Complications included anemia, diabetes mellitus, eclampsia and hypertension. A dose-response relationship was evident in the greater frequency of complications in mothers with quadruplets and more, compared with mother of triplets. These trends warrant consideration when counseling infertile couples seeking reproductive assistance. The investigators cautioned that lack of certain clinical details and possible coding errors need to be considered in interpreting the findings.

\section{Why Twins Fascinate}

\section{'Would-Be Twins'}

'Would-be twins' could be a casual term for virtual twins (VTs) — sameage unrelated siblings raised together since early infancy. These unique siblings offer researchers a good way to estimate the extent to which shared environments affect the development of human behavioral traits. Most VT pairs are formed in one of two ways: (1) couples are offered two same-age children at the same time, either by adoption agencies or by private sources; or (2) couples seeking adoption learn about (or are offered) an adoptive infant at about the time that a supposedly infertile woman becomes pregnant (or delivers a biological child). There are, however, rare VTs who come together through extraordinary circumstances.

I learned about Andrew R. and Edward S. from a colleague. (Their names have been altered to disguise their identity.) These adult VTs met most of the criteria for inclusion in my ongoing study: they differed in age by 9 months or less (Andrew and Edward were born just two weeks apart); they were always in the same school grade; and they were healthy at birth (see Segal, 2000a). However, they did not meet the criteria of living together before 1 year of age; in fact, they cannot say at precisely what age they began living together, although the best estimate is at some time before 15 months. Given this uncertainty, individual data will not be collected from these individuals. However, their life history events are of considerable research interest to individuals studying the behavioral development of twins and the cultural significance of twinning.

Andrew and Edward were born in June 1943, just 2 weeks apart, to two separate couples. Andrew's parents divorced leaving his mother to raise her young son on her own. Edward's mother died at birth, leaving his father to raise him and his older sister. Andrew's mother and Edward's father eventually met and married. This decision lead to a triple adoption: Andrew's mother adopted Edward and his sister, and Edward's father adopted Andrew. It didn't stop there - Andrew and Edward were told that they were twins. Their new birthday was calculated as the date exactly midway between their actual dates of birth. The reason that this blended family created 'twins' is unclear; however, the brothers speculated that, at that time, entering second marriages and adopting children may have been less accepted than they are currently. Having two sons born two weeks apart would have invited difficult questions and comments from friends and neighbors.

Edward and Andrew had little reason to suspect that their real relationship was other than what they were told. Like many DZ twins, they did not look alike-Andrew was taller and heavier while they were children, although Edward is now an inch taller due to a late adolescence growth spurt. Like about $20 \%$ of both MZ and DZ twin pairs, Andrew is lefthanded and Edward is right-handed (Annett, 2003). And like ordinary DZ twins, the brothers had a joint bar mitzvah when they turned 13. They shared a bedroom for a while when they were living at home, but they were not close growing up.

Both brothers were good at sports, but Andrew claims that he had an edge in this area. According to Edward, Andrew was physically stronger and Edward was 'a 98 pound weakling'. The brothers attended the same classes in grade school, but were often in different classes in junior high school and high school. Andrew claims that he performed better in the lower grades, until he 'went downhill' and Edward began to excel. Both brothers finished high school, but only Edward went to college. They owned and managed a joint business for a while until a disagreement prevented them from speaking for several years. They now speak by telephone occasionally and see each other about once each year.

When I spoke to Andrew and Edward on the telephone I was aware of another marked difference between them: Edward was eager to share the details of his unusual life story, while 
Andrew was not. Edward first explained how they learned the truth about their relationship.

When the brothers were 13 , Edward was visited by his biological maternal grandfather who showed him a picture of his biological mother. The teenager was shocked (as such aspects of adoption can be very painful), but he said nothing about it to anyone. He only searched the attic for further information, such as photographs and life history records. Then, when the brothers were 15 they had an argument. Andrew told Edward that because they were brothers he was allowed to act a certain way with him. Edward replied, 'I have news for you,' and told him that they were not twins, not even related.

Andrew remembers that Edward confronted him with this news when they were in their early teens, but he claims to have heard it before, probably from relatives. Teachers at school sometimes insisted that the boys' real dates of birth were different. 'I never put it together', Andrew said. But once he fully grasped the truth, it was 'weird'. The experience raised a lot of painful questions about identity and selfhood for both brothers. They stopped celebrating their birthdays together.

Andrew met his biological father for the first time when he was 16. His father had married four times and had had 12 children. Andrew observed, 'I am more like these halfbrothers and half-sisters than I am like my brother, Edward'.

Most virtual twins are aware of their relationship from a very early age. Andrew and Edward were unique in this respect because they believed that they were DZ twins until they were teenagers. It would be interesting to know if belief in twinship (in the absence of any biological link) enhances behavioral similarity in siblings growing up together. Of course, the parents in this family knew the nature of their son's real relationship, but what if they had not? I am aware of one case, involving accidental switching of twins at birth, in which the parents and sons had no reason to doubt that the children were DZ twins. The rarity of these cases most likely precludes a formal analysis of how belief in twinship (in the absence of a genetic relationship) affects sibling development. However, based on the lack of association between similarity of parental treatment of twins and similarity of twins' behavioral outcomes (see Segal, 2000b), it is unlikely that belief in twinship would significantly affect behavioral resemblance.

Blended families, half-siblings and step-siblings have becoming increasingly common in recent years. Such unusual family arrangements have assisted developmental psychologists and behavioral geneticists in identifying genetically and socially informative kinships for psychological studies. The psychological consequences in this family, and in others, strongly suggest that parents inform their children about their biological backgrounds so they are not disillusioned and disappointed in the future.

The brothers' parents are now in their 90s. Their mother still claims that she has twins.

\section{'Want To Be' Twins}

'Want to be' Twins could be an informal label for twins reared apart from birth. These siblings are the mirrorimage of virtual twins - twins reared apart share their genes, but not their environments, while virtual twins share their environments, but not their genes.

A special panel, 'Ethical Issues in Twin Studies', was held as part of the 2004 International Congress on Twin Studies. One panelist, Inge Sadowsky, delivered a powerful talk about her experiences associated with adopting her young son from Haiti - this boy turned out to be part of a reared-apart twin pair, most likely MZ. Her son's twin brother was adopted by a couple living in another European country. The twins were born on January 12, 1999. They had spent about 3 years together (in their biological home and in an orphanage) before they were separated. The Danish couple had adopted their son when he was 3.5 years old, while his twin was adopted by another couple when he was 4 years. Their son speaks about his brother from time to time, and he misses him. He has become friendly with another identical twin pair at school.
At the end of July the court (in the country of the other family) decided that the twin boys should not have contact growing up. According to Ms. Sadowsky, 'the judges have decided that it is up to the (other) adoptive parents if, and how, they shall have contact with each other'.

Studying twins reared apart is one of the best methods for assessing genetic and environmental influences on behavioral traits. Twins raised in different countries increase the power of this design because the twins' rearing environments probably diverge more markedly than those of twins reared in similar cultures. In cases in which the multiple birth status of one, or both twins, is known, the location of the co-twin may be uncertain so families could not bring the twins together even if they wanted to.

However, when this information is known, most psychologists, social workers and families try to reunite the twins, not keep them apart. Most adult reunions are enormously happy experiences for the twins, although most of them regret their lost childhood, knowing that those years cannot be recovered.

In the Danish case, the two families are aware of the identity and location of their sons' parents. This case is complex and a great deal is unknown to me; most of the documents are not written in English. However, it would seem that efforts toward allowing the children to know one another would be to their benefit - especially since memories of having a twin sibling who is alive and well, but no longer present, are painful and frustrating.

\section{Unusual Parents}

Twin boys, Yosef and Yaakov, were born to a paralyzed couple, Shmuel and Rebecca Klein, in California (Wenig, 2004). The babies were conceived through in-vitro fertilization and born after 35 weeks. Both of the twins were healthy at birth - Yosef weighed 5 pounds and Yaakov weighed 5 pounds, 3 ounces. Raising twins is a challenging task for able-bodied mothers and fathers, but becomes even more so when parents are physically disabled. Like ordinary couples, the Kleins will discover creative methods 
for caring for their twins as infants and beyond - local California television aired a touching piece showing them transferring the twins from their car to their second floor apartment. The Kleins may also pave the way for other disabled mothers and fathers with multiple birth children.

\section{Twinsburg, Ohio}

Everyone knows about Twinsburg, Ohio - the scene of the annual Twins Days Festival where several thousand twins gather to celebrate being part of a multiple birth set. But less well known are the different research projects conducted in tents set up amidst the games, contests and crafts booths. In summer, 2004, twins lined up for dermatoglyphic (fingerprint) studies. According to one journalist, there was something mysterious about this work: It seemed that festival staff wondered if the Secret Service was somehow involved.

The journalist contacted the Secret Service, but was referred to the International Association for Identification (IAI). The IAI chairman insisted that his organization was responsible for this twin work. He explained that the study was for research purposes only, and was intended to help experts distinguish fingerprints provided by different people. He also indicated that the United States government was assisting in this effort and that not everyone at the IAI would be able to analyze the data - prompting the journalist to ask for 'a little more openness from the Feds'.

\section{$M Z \times T w o$}

A quadruplet set composed of two sets of MZ twins, was born in August, 2004 to a Wynwood, Pennsylvania family (Associated Press, 2004). One MZ pair was male and the other pair was female. The mother was a twin herself, although her zygosity was not reported. She turned 34 years old on the day of delivery, so she was approaching the age interval at which the chances of DZ twinning increase.

The article indicated that the odds of giving birth to $\mathrm{MZ} / \mathrm{DZ}$ quadruplets were one in one million; however, that was the figure given for naturally occurring quadruplets (Bryan, 1983). It would seem that the rarity of delivering two sets of MZ twins simultaneously would be even greater.

\section{References}

Annett, M. (2003). Cerebral asymmetry in twins: Predictions of the right shift theory. Neuropsychologia, 41, 469-479.

Associated Press. (2004, August 16). Woman gives birth to two sets of identical twins.

Bryan, E. M. (1983). The nature and nurture of twins. London: BallièreTindall.

Gottesman, I. I. (1991). Schizophrenia genesis: The origins of madness. New York: W. H. Freeman.

Kates, W. R., Burnette, C. P., Eliez, S., Strunge, L. A., Kaplan, D., Landa, R., Reiss, A. L., \& Pearlson, G. D. (2004). Neuroanatomic variation in monozgotic twin pairs discordant for the narrow phenotype for autism. American Journal of Psychiatry, 161, 539-546.
OMD (1997-2004). On-line medical dictionary. Newcastle on Tyne, UK: Department of Oncology, University of Newcastle on Tyne.

Paramei G. V., Bimler, D. L., \& Mislavsaia, N. O. (2004). Colour perception in twins: Individual variation beyond common genetic inheritance. Clinical and Experimental Optometry, 87, 305-312.

Raykan, V. K., Blewitt, M. E., Druker, R., Preis, J. I., \& Whitlaw, E. (2002). Metastable epialleles in mammals. Trends in Genetics, 18, 348-351.

Segal, N. L. (2000a). Virtual twins: New findings on within-family environmental influences on intelligence. Journal of Educational Psychology, 92, 442-448.

Segal, N. L. (2000b). Entwined lives: Twins and what they tell us about human behavior. New York: Plume.

Silber, S. J. (1978). Transplantation of a human testis for anorchia. Fertility and Sterility, 30, 181-187.

Thorpe, K., Greenwood, R., Eivers, A., \& Rutter, M. (2001). Prevalence and developmental course of 'secret language'. International Journal of Language and Communication Disorders, 36, 43-62.

Two of a Kind. (2004, August 14). The Economist, pp. 70-71.

Wen, S. W., Demissie, K., Yang, Q., \& Walker, M. C. (2004). Maternal morbidity and obstetric complications in triplet pregnancies and quadruplet and higher-order multiple pregnancies. American Journal of Obstetrics and Gynecology, 191, 254-258.

Wenig, G. (2004, September 3). Twins Bring Hope to Disabled Couple. Jewish Journal, p. 20. 